\title{
INFLUÊNCIA DE CHUVA SIMULADA APÓS APLICAÇÃO DE HERBICIDAS EM PÓS-EMERGÊNCIA, SOBRE O CONTROLE DE PLANTAS DANINHAS, EM SOLO COM DOIS NÍVEIS DE UMIDADE ${ }^{1}$
}

\author{
MARCOS L.R. BASTIANI ${ }^{2}$, ANTÔNIO A. SILVA ${ }^{3}$, FRANCISCO A. FERREIRA ${ }^{3}$ e ANTÔNIO A. CARDOSO
}

\section{RESUMO}

Dois experimentos foram conduzidos em 1995, em casa-de-vegetação do Departamento de Fitotecnia da Universidade Federal Viçosa, Viçosa-MG, com o objetivo de avaliar a influência da chuva após a aplicação de herbicidas, no controle de capim-marmelada (Brachiaria plantaginea L.) e picão-preto (Bidens pilosa L.), na cultura do milho (Zea mays L.), em solo com dois níveis de umidade. Foram aplicados o nicosulfuron em duas formulações (SC e WDG) e as misturas nicosulfuron + atrazine e atrazine + óleo, com intervalos de $0,15,30,60$ e $120 \mathrm{~min}$ entre a aplicação do herbicida e a ocorrência de $30 \mathrm{~mm}$ de chuva simulada. O delineamento experimental foi o de blocos casualizados, com quatro repetições, dispostos em arranjo fatorial $5 \times 5$, sendo o primeiro fator constituído de herbicidas mais testemunha, e o segundo de cinco tempos para ocorrência de chuva. Os parâmetros estimados foram biomassa fresca, biomassa seca e altura de plantas (apenas para picão-preto). Após emergência das plântulas, o teor de umidade do solo foi mantido próximo à capacidade de campo $(41,3 \%)$ para um experimento e, umidade mantida de forma a submeter as plantas à condição de estresse hídrico $(24,7 \%)$ para o outro. A eficiência do nicosulfuron no controle de capim-marmelada foi maior com o aumento do intervalo sem chuva até 30 min após a aplicação do herbicida, para as plantas cultivadas em solo com elevada umidade. Em solo com baixa umidade, a eficiência do controle foi muito baixa, mesmo quando a chuva ocorreu 120 min após aplicação. O controle de picão-preto com nicosulfuron SC ou WDG foi muito baixo (< 50\%), mesmo em boas condições de umidade do solo. A mistura nicosulfuron + atrazine proporcionou controle do capim-marmelada, semelhante à aplicação isolada de nicosulfuron e excelente controle de picãopreto em ambas as condições de umidade do solo. Atrazine+óleo foi ineficiente para o controle de capim-marmelada $(<$ de $75 \%)$ e altamente eficiente para controle de picão-preto (100\%), independente da condição de umidade do solo e do intervalo de tempo para ocorrência de chuva simulada após aplicação.

Palavras-chave: Brachiaria plantaginea, Bidens pilosa, Zea mays, atrazine, nicosulfuron.

\section{ABSTRACT \\ Effects of rainfall on weed control in soil with two moisture levels, after herbicide applied in postemergence}

Two experiments were conducted on a greenhouse, at Fitotecnia Department at University Federal of Viçosa, Viçosa-MG, intending to evaluate simulated rain influence after herbicides application, on the control of Brachiaria plantaginea and Bidens pilosa on corn

\footnotetext{
${ }^{1}$ Recebido para publicação em 25/03/98 e na forma revisada em 27/09/99. Trabalho financiado pelo CNPq.

${ }^{2}$ Eng $^{\circ}$ Agr $^{\circ}$, Pós-graduando no DFT/UFV, Secretaria da Pós-graduação, DFT/UFV, Viçosa/MG, cep: 36571-000.

${ }^{3} \mathrm{Eng}^{\mathrm{o}} \mathrm{Agr}^{\mathrm{o}}$, Professor Adjunto no DFT/UFV, Viçosa/MG, CEP: 36571-000.
} 
(Zea mays) crop, on soil with two moisture levels. Nicosulfuron on two formulations (SC and WDG) and the mixtures nicosulfuron+atrazine and atrazine+oil were applied, with $0,15,30,60$ and 120 minutes intervals between herbicide application and a $30 \mathrm{~mm}$ simulated rain occurrence. Estimated parameters were fresh biomass, dry biomass and plants height. After seedlings emergence two experiments were undertaken; on the first one soil moisture level was kept near to field capacity $(41.3 \%)$, and on the other one seedlings were submitted to water stress $(24.7 \%$ of soil moisture). Nicosulfuron efficiency on $B$. plantaginea control was greater when rain absence rain interval was increased until to 30 minutes after herbicide application, for plants grown on soil with high moisture

\section{INTRODUÇÃO}

São muitos os herbicidas e/ou misturas recomendados para o controle de plantas daninhas na cultura do milho (Zea mays L.). A maioria desses produtos são usados em pré-emergência, sendo poucas as opções para aplicação em pósemergência (Silva e Melhorança, 1991). Com o incremento da área de milho cultivada pelo sistema de plantio direto, surgiu a necessidade de se desenvolver novos herbicidas que fossem recomendados em pós-emergência, sendo o nicosulfuron um desses produtos (Pinto et al., 1993; Silva \& Altoé, 1993; Ferreira et al., 1996). Esse herbicida é seletivo para híbridos de milho (Green \& Ulrich, 1993), para uso em pósemergência da cultura e das plantas daninhas, com excelente ação sobre diversas espécies de monocotiledôneas (gramíneas) e dicotiledôneas, conforme comprovaram Ferreira et al. (1996).

Segundo Devine et al. (1983), umidade do solo, temperatura e umidade relativa do ar interferem no comportamento dos herbicidas na planta. Quando uma ou mais daquelas condições não são satisfatórias, o controle de plantas daninhas com produtos recomendados em pósemergência, pode tornar-se insatisfatório, não atingindo os níveis desejáveis de controle. Deuber content. On soil with low moisture content control efficiency was very poor, even when rain occurred 120 minutes after herbicide application. Bidens pilosa control with nicosulfuron SC or WDG was poor, even on humid soil. The mixture nicosulfuron+atrazine resulted on B. plantaginea control similar to that when nicosulfuron was applied alone, and excellent control of B. pilosa, on both soil moisture conditions. Atrazine+oil was inefficient for $B$. plantaginea control and highly efficient for $B$. pilosa control, independent of soil moisture and of time interval for simulated rain occurrence after herbicide application.

Key words: Brachiaria plantaginea, Bidens pilosa, Zea mays, atrazine, nicosulfuron.

(1992) cita estudos feitos com vários herbicidas, mostrando que a absorção é limitada pela quantidade do produto que atravessa a cutícula da folha e esta é influenciada pelas condições ambientes onde a planta daninha está se desenvolvendo. Diversos autores observaram significativa redução na atividade de herbicidas, quando esses eram aplicados sobre plantas daninhas desenvolvidas em solos com baixa umidade (Retzinger et al., 1983; Kells et al., 1984; Harrison \& Wax, 1986; Peregoy et al., 1990), caracterizada como condição de estres se hídrico para essas plantas.

Diversas alterações metabólicas e fisiológicas como: redução da taxa fotossintética (Taiz \& Zeiger, 1991), espessamento da cutícula, menor permeabilidade das membranas e alterações na osmorregulação (Hess, 1994), que se desenvolvem nas plantas sob condições de estresse hídrico, influenciam diretamente a absorção e translocação de água e outras substâncias (Kramer, 1987), afetando, conseqüentemente, a atividade de herbicidas aplicados em pós-emergência (Waldecker \& Wyse, 1985; Velini \& Trindade, 1992).

Precipitações pluviais após a aplicação do herbicida podem também comprometer o seu desempenho em pós-emergência (Behrens \& 
Elakkad, 1981). Assim, o intervalo de tempo entre a aplicação e a ocorrência de chuvas (Anderson \& Arnold, 1984), bem como a quantidade e a intensidade de chuva (Hammerton, 1967), além dos diferentes herbicidas e tipos de formulações, influem decididamente na eficiência de controle das plantas daninhas.

Este trabalho tem como objetivo avaliar a influência da chuva após a aplicação de duas formulações de nicosulfuron (SC e WDG), da mistura de nicosulfuron+atrazine e de atrazine+óleo, no controle do capim-marmelada e do picão-preto na cultura do milho cultivada em vasos preenchidos com solo com dois teores de umidade.

\section{MATERIAL E MÉTODOS}

Dois experimentos foram conduzidos em casa de vegetação, usando-se vasos de $15 \times 15 \times 18 \mathrm{~cm}$, internamente revestidos com sacos de polietileno. Os vasos foram preenchidos com $3,0 \mathrm{dm}^{3}$ de solo Podzólico Vermelho-Amarelo câmbico fase terraço (PVc), coletado a uma profundidade de $0-10 \mathrm{~cm}$, contendo as seguintes características: $\mathrm{pH}$ em água $(4,9), \mathrm{P}\left(6,3 \mathrm{mg} / \mathrm{dm}^{3}\right)$, $\mathrm{K}\left(78 \mathrm{mg} / \mathrm{dm}^{3}\right), \mathrm{Ca}^{+2}\left(4,2 \mathrm{cmol}_{\mathrm{c}} / \mathrm{dm}^{3}\right), \mathrm{Mg}^{+2}(0,9$ $\left.\mathrm{cmol}_{\mathrm{d}} / \mathrm{dm}^{3}\right), \mathrm{Al}^{+3}\left(0,02 \mathrm{cmol}_{\mathrm{c}} / \mathrm{dm}^{3}\right)$, argila $(52 \%)$ e matéria orgânica $(4,2 \%)$.

O substrato (com umidade de T.F.S.A.) foi homogeneizado, misturando com superfosfato simples e calcário dolomítico, nas quantidades de 15 e $8 \mathrm{~g} / \mathrm{vaso}$, respectivamente, de acordo com os resultados da análise química do solo apresentados acima. As sementes de capimmarmelada (Brachiaria plantaginea L.), picãopreto (Bidens pilosa L.) e milho ('AG 201') foram semeadas em seguida. Houve necessidade da quebra de dormência das sementes de capimmarmelada, com escarificação em solução de $\mathrm{H}_{2} \mathrm{SO}_{4} 1 \mathrm{~N}$, por $15 \mathrm{~min}$, proposta para Brachiaria decumbens L., de acordo com as "Regras para Análise de Sementes" (BRASIL, 1992). A irrigação foi diária, procurando-se manter o solo com umidade próxima à capacidade de campo. Após a completa germinação das sementes foi feito um desbaste, deixando-se por vaso: uma planta de milho; cinco de picão-preto; e quatro de capim-marmelada.

$\mathrm{O}$ teor de umidade do solo no primeiro experimento foi mantido, da germinação das sementes até a colheita das plantas, próximo à capacidade de campo (41,3\%). A condição de estresse hídrico para as plantas (solo com $24,7 \%$ de umidade) no segundo experimento foi mantida da germinação das sementes até a aplicação dos herbicidas, após a qual, a irrigação foi mantida igual à do primeiro ensaio. Os teores de umidade do solo foram determinados previamente em laboratório, com a obtenção da curva característica de umidade do solo e aplicados aos vasos, logo após feito o desbaste das plantas. Diariamente era feito o controle dos teores de umidade do solo, utilizando-se um tensiômetro digital e pesagens de cada vaso, visando repor a água evapotranspirada durante o transcorrer do dia.

Para a determinação da curva característica de umidade, trabalhou-se com sete pontos e três repetições, utilizando-se funil de Buchner e câmera de pressão de Richards. Os valores de umidade obtidos à base de massa (g/g), foram transformados em umidade à base de volume, elaborando-se em papel simi-log a curva de retenção de água para o solo a ser utilizado no experimento.

$\mathrm{O}$ delineamento experimental usado foi o de blocos casualizados num arranjo fatorial com quatro herbicidas mais duas testemunhas (com e sem capina) e cinco intervalos de tempo entre a aplicação e a ocorrência de chuva simulada. Os herbicidas atrazine + nicosulfuron $(1000+$ 40 g.ha $\left.{ }^{-1}\right)$; nicosulfuron $\quad$ SC-“suspensão concentrada" (60 g.ha- $\left.{ }^{-1}\right)$; nicosulfuron WDG"grânulos dispersíveis em água" (60 g.ha $\left.{ }^{-1}\right)$;e atrazine+óleo $\left(2400+1800\right.$ g.ha $\left.^{-1}\right)$ foram aplicados aos 24 dias após emergência das plantas de milho, quando essas apresentavam de cinco a sete folhas, o capim-marmelada três a quatro perfilhos e o picão-preto quatro pares de folhas definitivas. Foi usado um pulverizador costal, pressurizado a $\mathrm{CO}_{2}$, calibrado para aplicar 200 L.ha ${ }^{-1}$. A simulação de chuva 
com $30 \mathrm{~mm}$ (intensidade de $60 \mathrm{~mm} / \mathrm{h}$ ) foi feita aos $0 ; 15 ; 30 ; 60$ e 120 min após a aplicação dos herbicidas, utilizando-se um simulador de chuvas para vasos. O sistema é constituído, basicamente, por uma mesa de aço com tampa perfurada (onde são colocados os vasos) e uma barra de pulverização com dois bicos "tipo leque", nas laterais. A barra de pulverização fica suspensa sobre a mesa, em altura regulável, sendo a intensidade da chuva regulada pela altura da barra, pela pressão a qual a água é submetida dentro do simulador (controlada por um manômetro) e pela posição dos vasos sobre a mesa.

Visando a uma melhor caracterização das plantas, cultivadas em solo próximo à umidade de campo e daquelas mantidas sob estresse hídrico, foram determinadas a taxa fotossintética, a transpiração, a condutância estomática e a concentração interna de $\mathrm{CO}_{2}$, por ocasião da aplicação dos herbicidas, utilizando-se o aparelho analisador de gases no infravermelho (IRGA). Essas avaliações foram realizadas por ocasião da aplicação dos tratamentos, a partir de seis vasos escolhidos ao acaso, em cada um dos experimentos. As demais características (altura de planta e biomassa seca) foram avaliadas na colheita do experimento, aos 28 dias após as aplicações dos tratamentos (D.A.T). As características avaliadas foram submetidas à análise de variância e de regressão e as médias comparadas a $5 \%$ de probabilidade pelo teste de Tukey, utilizando-se o programa estatístico SAEG (UFV) na "versão 5.0", como instrumento de auxilio nas análises.

\section{RESULTADOS E DISCUSSÃO}

No momento da aplicação dos tratamentos, aos 24 dias após emergência (DAE), as plantas de capim-marmelada (B. plantaginea) apresentavam-se com três a quatro perfilhos, e altura média de $25 \mathrm{~cm}$. Já as plantas de picãopreto (B. pilosa) estavam, em média, com $20 \mathrm{~cm}$ de altura e com quatro a cinco pares de folhas, enquanto que, as de milho, apresentavam de cinco a sete folhas e uma altura média de $45 \mathrm{~cm}$.

As plantas de capim-marmelada cultivadas em condições de solo úmido tiveram sua biomassa seca reduzida em função do tempo transcorrido entre a aplicação dos herbicidas e a ocorrência da chuva simulada, até $30 \mathrm{~min}$, quando se utilizou herbicida nicosulfuron (SC e WDG) isoladamente ou em mistura com atrazine (Tabela 1 e Figura 1). Verificou-se também que esses tratamentos foram superiores ao tratamento com atrazine+óleo (Tabela 1 e Figura 1).

Em plantas da mesma espécie, cultivadas em solo com baixa umidade (estresse hídrico), os herbicidas não apresentaram melhoria na sua eficiência de controle do capim-marmelada com o aumento do intervalo de tempo entre as aplicações dos herbicidas e a ocorrência de chuva simulada (Figura 2), mesmo considerando um intervalo de $120 \mathrm{~min}$. Observou-se, porém, que os tratamentos com herbicidas foram superiores à testemunha. Os resultados foram semelhantes entre os diversos herbicidas (Tabela 2). Deve-se considerar que as condições de estresse hídrico induzem as plantas a apresentarem menor atividade fisiológica (taxa fotossintética, condutância estomática, concentração interna de $\mathrm{CO}_{2}$ e transpiração), conforme mostram as Figuras 5 e 6 . O estresse hídrico facilita a desidratação e o espessamento da cutícula, o desenvolvimento de células menores na epiderme e com parede celular mais espessa, dificultando a absorção e/ou a penetração dos herbicidas nas folhas e, conseqüentemente, favorecendo a lavagem dos mesmos pela água da chuva, face à maior permanência do produto sobre o limbo foliar. Segundo Kramer (1987), em plantas cultivadas sob condições de déficit hídrico, a translocação de água e outras substâncias também ficam comprometidas, já que há redução da transpiração e conseqüentemente do fluxo de massa, o que dificulta o movimento do herbicida até seu sítio de ação na célula vegetal. 
TABELA 1. Biomassa seca $(\mathrm{g})^{1}$ de Brachiaria plantaginea aos 28 DAT, em função da ocorrência de $30 \mathrm{~mm}$ de chuva aos $0 ; 15 ; 30 ; 60$ e $120 \mathrm{~min}$ após aplicação dos tratamentos sobre as plantas cultivadas em solo úmido. Viçosa, MG, 1996.

\begin{tabular}{|c|c|c|c|c|c|c|}
\hline \multirow{3}{*}{ Herbicidas + Testemunha } & \multirow{3}{*}{$\begin{array}{c}\text { Doses } \\
\text { (g.i.a./ha) }\end{array}$} & \multicolumn{5}{|c|}{ Tempo: aplicação/ocorrência de chuva simulada } \\
\hline & & $0 \mathrm{~min}$. & $15 \mathrm{~min}$. & $30 \mathrm{~min}$. & 60 mnin. & $120 \mathrm{~min}$. \\
\hline & & \multicolumn{5}{|c|}{ Biomassa Seca $(g)^{1}$} \\
\hline Nicosulfuron+Atrazine & $40+1000$ & $29,57 \mathrm{~b}$ & $31,02 \mathrm{bc}$ & $15,95 \mathrm{~b}$ & $16,40 \mathrm{c}$ & $14,25 \mathrm{c}$ \\
\hline Nicosulfuron SC & 60,0 & $34,70 \mathrm{ab}$ & $22,15 \mathrm{c}$ & $11,20 \mathrm{~b}$ & $12,67 \mathrm{c}$ & $12,37 \mathrm{c}$ \\
\hline Nicosulfuron WDG & 60,0 & $31,40 \mathrm{~b}$ & $25,20 \mathrm{bc}$ & $14,95 \mathrm{~b}$ & $14,05 \mathrm{c}$ & $17,35 \mathrm{c}$ \\
\hline Atrazine+ Óleo & $2400+1800$ & $33,77 \mathrm{ab}$ & $34,27 \mathrm{~b}$ & $32,97 \mathrm{a}$ & $34,15 \mathrm{~b}$ & $28,17 \mathrm{~b}$ \\
\hline Testemunha & ------- & $42,05 \mathrm{a}$ & $44,17 \mathrm{a}$ & $41,97 \mathrm{a}$ & $46,60 \mathrm{a}$ & $47,95 \mathrm{a}$ \\
\hline
\end{tabular}

1/ - Médias seguidas da mesma letra na coluna não diferem entre si a 5\% de probabilidade, pelo teste de Tukey.

DAT - Dias após tratamento.

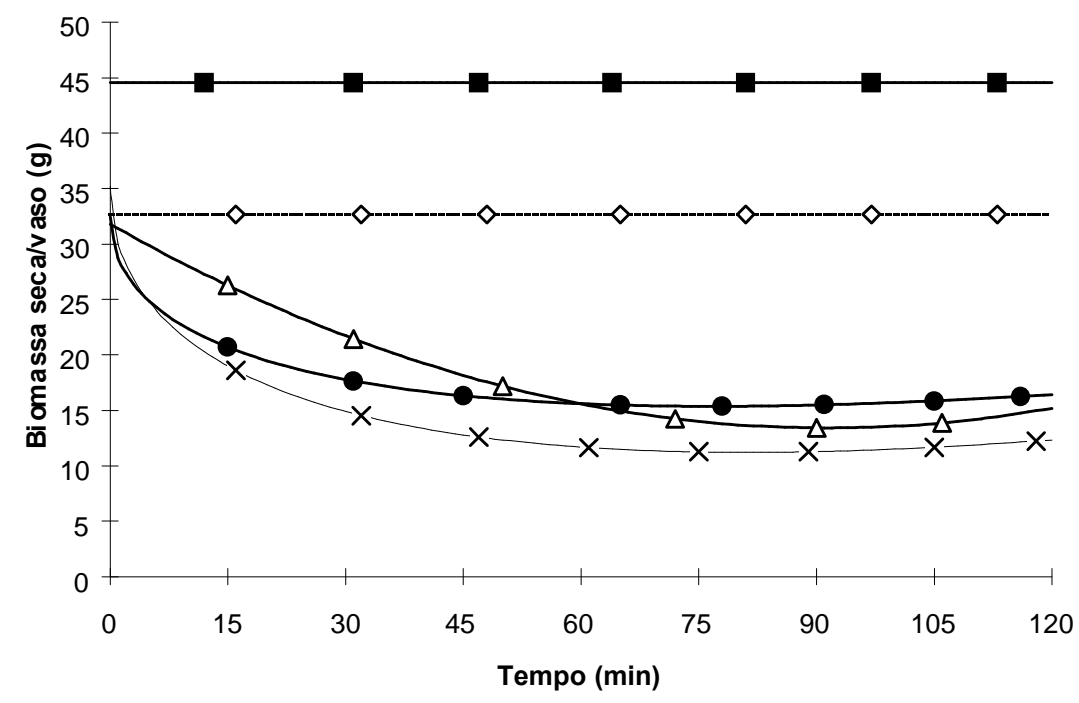

$\begin{array}{llr}\text { Nicosulfuron+Atrazine } & \mathrm{Y}=31,1803-0,4024 * * \mathrm{X}+0,0022 * * \mathrm{X}^{2} & \mathrm{R}^{2}=0,7733 \\ \text { Nicosulfuron SC } & \mathrm{Y}=35,1767+0,2953 * * \mathrm{X}-5,3203 * * \mathrm{X}^{0,5} & \mathrm{R}^{2}=0,9382 \\ \text { Nicosulfuron WDG } & \mathrm{Y}=32,44-3,8919 * * \mathrm{X}^{0,5}+0,2218^{* *} \mathrm{X} & \mathrm{R}^{2}=0,8537 \\ \text { Atrazine+Óleo } & \mathrm{Y}=\mathrm{y}=32,66 & \\ \text { Testemunha } & \mathrm{Y}=\mathrm{y}=44,55 & \end{array}$

FIGURA 1. Biomassa seca, em gramas, de Brachiaria plantaginea, aos 28 DAT, em função do tempo de aplicação de 30 mm de chuva, em condições de solo úmido. Viçosa, MG, 1996. 
TABELA 2. Biomassa seca $(\mathrm{g})^{1}$ de Brachiaria plantaginea aos 28 DAT em função da ocorrência de $30 \mathrm{~mm}$ de chuva aos $0 ; 15 ; 30 ; 60$ e 120 min após aplicação dos tratamentos sobre plantas cultivadas sob estresse hídrico. Viçosa, MG, 1996.

\begin{tabular}{|c|c|c|c|c|c|c|}
\hline \multirow{3}{*}{ Herbicida+Testemunha } & \multirow{3}{*}{$\begin{array}{c}\text { Doses } \\
\text { (g.i.a./ha) }\end{array}$} & \multicolumn{5}{|c|}{ Tempo: aplicação/ocorrência de chuva simulada } \\
\hline & & 0 min. & $15 \min$. & $30 \mathrm{~min}$. & 60 mnin. & $120 \mathrm{~min}$. \\
\hline & & \multicolumn{4}{|c|}{ Biomassa Seca } & \\
\hline Nicosulfuron+Atrazine & $40+1000$ & $22,12 \mathrm{~b}$ & $30,12 \mathrm{~b}$ & $20,90 \mathrm{~b}$ & $28,77 \mathrm{~b}$ & $23,20 \mathrm{~b}$ \\
\hline Nicosulfuron SC & 60,0 & $16,52 \mathrm{~b}$ & $16,80 \mathrm{c}$ & $19,65 \mathrm{~b}$ & $19,90 \mathrm{c}$ & $17,82 \mathrm{~b}$ \\
\hline Nicosulfuron WDG & 60,0 & $22,67 \mathrm{~b}$ & $23,35 \mathrm{bc}$ & $17,77 \mathrm{~b}$ & $21,05 \mathrm{bc}$ & $21,90 \mathrm{~b}$ \\
\hline Atrazine+ Óleo & $2400+1800$ & $22,75 \mathrm{~b}$ & $24,07 \mathrm{bc}$ & $25,52 \mathrm{~b}$ & $22,55 \mathrm{bc}$ & $21,70 \mathrm{~b}$ \\
\hline Testemunha & ------- & $41,30 \mathrm{a}$ & $41,05 \mathrm{a}$ & $41,17 \mathrm{a}$ & $44,97 \mathrm{a}$ & $41,12 \mathrm{a}$ \\
\hline
\end{tabular}

1/ - Médias seguidas da mesma letra na coluna não diferem entre si a 5\% de probabilidade, pelo teste de Tukey.

DAT - Dias após tratamento.

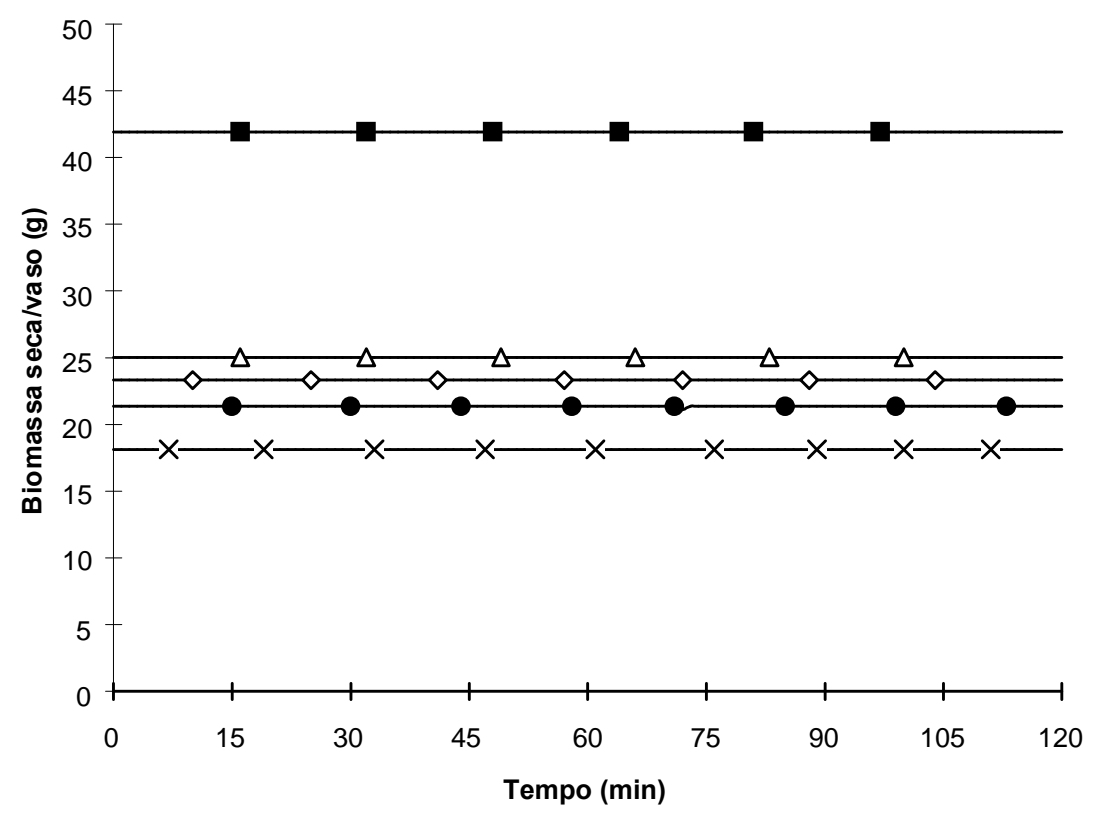

Nicosulfuron+Atrazine Nicosulfuron SC

Nicosulfuron WDG Atrazine+Óleo

Testemunha

$$
\begin{aligned}
& \mathrm{Y}=\mathrm{y}=25,02 \\
& \mathrm{Y}=\mathrm{y}=18,14 \\
& \mathrm{Y}=\mathrm{y}=21,35 \\
& \mathrm{Y}=\mathrm{y}=23,32 \\
& \mathrm{Y}=\mathrm{y}=41,92
\end{aligned}
$$

FIGURA 2. Biomassa seca, em gramas, de Brachiaria plantaginea, aos 28 DAT, em função do tempo de aplicação de 30 mm de chuva em condições de estresse hídrico. Viçosa, MG, 1996. 
As plantas de picão-preto apresentaram comportamento fisiológico contrastante com as de capim-marmelada e de milho (Figuras 5 e 6), mantendo normais a taxa fotossintética, a condutância estomática, a concentração interna de $\mathrm{CO}_{2}$ e a transpiração, mesmo sob condições de baixa umidade no solo. Os dados sugerem que para esse nível de umidade, no solo em questão $(24,7 \%)$, as plantas de picão-preto adaptaram-se mais facilmente que as de capim-marmelada e de milho, não ficando necessariamente caracterizada para essa espécie, a condição de estresse hídrico.

O herbicida "atrazine+óleo" não foi eficiente no controle de plantas de capimmarmelada, tanto para aquelas crescidas em solo úmido, quanto em condições de déficit hídrico (Tabelas 1 e 2 e Figuras 1 e 2). Deve-se considerar que esses resultados foram observados em plantas que estavam em adiantado estádio de desenvolvimento no momento da aplicação desse herbicida ( 3 a 4 perfilhos; aplicações realizadas 24 dias após emergência das plantas, ou 24 DAE). Em condições de campo o mesmo herbicida apresentou controle satisfatório quando aplicado sobre essa gramínea em estádios mais precoces de desenvolvimento (Ferreira et al., 1996).

Como altura de planta foi a caracteristica que melhor representou as diferenças entre as plantas de picão-preto submetidas aos diversos tratamentos nas duas condições de umidade do solo, esta foi mantida para a discussão dos resultados obtidos para a espécie em questão. Os tratamentos com "atrazine+óleo" foram altamente eficientes para o controle de picão-preto, nas duas condições de umidade de solo consideradas. Não foi possível analisar a influência do intervalo entre a aplicação e a ocorrência de chuva, visto que o atrazine tem melhor efeito quando aplicado ao solo, sendo melhor absorvido pelo sistema radicular que pela folha, ocorrendo $100 \%$ de controle em ambas as condições de umidade do solo. O herbicida nicosulfuron (SC ou WDG) apresentou baixa toxicidade sobre picão-preto (Tabela 3, e Figura 3), observando-se máxima ação desse herbicida quando a chuva simulada ocorreu 60 min após a aplicação. Foi observada diferença de comportamento entre as duas formulações do nicosulfuron (SC e WDG) sobre a altura de plantas de B. pilosa. Plantas pulverizadas com a formulação "SC" apresentaram menor altura (Tabela 3) que aquelas pulverizadas com nicosulfuron "WDG", a partir do intervalo de 30 min, o que sugere melhor absorção do produto quando usado na formulação "SC". Em condições de estresse hídrico, o efeito do nicosulfuron foi ainda menor (Tabelas 4 e 6, e Figura 4). Essa baixa eficiência de controle, observada para o picão-preto, discorda de resultados observados em condições de campo onde o herbicida nicosulfuron apresentou controle satisfatório sobre essa espécie (Ferreira et al., 1996). Deve-se considerar o ambiente específico de casa-de-vegetação e que este produto tem maior atividade herbicida quando aplicado sob plantas em estádios mais precoces de desenvolvimento (um a dois pares de folhas). Biomassa seca de plantas dessa espécie não foi um bom indicador para discussão nesse trabalho (Tabela 6) e, para que a hipótese de um comportamento atípico do picão preto submetido a estes tratamentos seja confirmada, novos estudos precisam ser realizados no futuro.

Considerando-se as condições de solo úmido, para o mesmo intervalo entre a aplicação dos tratamentos e a ocorrência de chuva simulada, os tratamentos contendo nicosulfuron apresentaram melhor controle de capimmarmelada (Figuras 1 e 2 ), enquanto os tratamentos com atrazine foram mais eficientes no controle de picão-preto (Figuras 5 e 6 ).

Para se avaliar o efeito da competição de plantas sobre a cultura do milho, utilizou-se a biomassa seca desta cultura. Este parâmetro também permitiu avaliar possíveis efeitos dos tratamentos sobre o desenvolvimento do milho. Todavia, este trabalho não teve como objetivo avaliar a seletividade de herbicidas para a cultura em questão. Observou-se que a biomassa seca neste caso, não foi influenciada pelos herbicidas utilizados, nem pelo tempo transcorrido entre a aplicação e a ocorrência de chuva (Tabela 5). Nos tratamentos em que o controle de plantas daninhas não foi eficiente, verificou-se redução significativa do acúmulo da biomassa do milho, quando comparado à testemunha com capina (Tabela 5). 
TABELA 3. Altura de plantas $(\mathrm{cm})^{1}$ de Bidens pilosa aos 28 DAT, em função da ocorrência de $30 \mathrm{~mm}$ de chuva aos $0 ; 15 ; 30 ; 60$ e 120 min e após aplicação dos tratamentos sobre plantas cultivadas em solo úmido. Viçosa, MG, 1996.

\begin{tabular}{lccccccc}
\hline \multirow{2}{*}{ Herbicidas+Testemunha } & \multirow{2}{*}{$\begin{array}{c}\text { Doses } \\
\text { (g.i.a./ha) }\end{array}$} & \multicolumn{5}{c}{ Tempo: aplicação / ocorrência de chuva simulada } \\
\cline { 3 - 8 } & $40+1000$ & $0,00 \mathrm{~b}$ & $0,00 \mathrm{c}$ & $0,00 \mathrm{~d}$ & $0,00 \mathrm{~d}$ & $0,00 \mathrm{~d}$ \\
Nicosulfuron+Atrazine & 60,0 & $37,75 \mathrm{a}$ & $39,25 \mathrm{ab}$ & $22,00 \mathrm{c}$ & $18,25 \mathrm{c}$ & $15,75 \mathrm{c}$ \\
Nicosulfuron SC & 60,0 & $37,75 \mathrm{a}$ & $34,00 \mathrm{~b}$ & $30,25 \mathrm{~b}$ & $29,50 \mathrm{~b}$ & $26,25 \mathrm{~b}$ \\
Nicosulfuron WDG & $2400+1800$ & $0,00 \mathrm{~b}$ & $0,00 \mathrm{c}$ & $0,00 \mathrm{~d}$ & $0,00 \mathrm{~d}$ & $0,00 \mathrm{~d}$ \\
Atrazine+ Óleo & - & $43,00 \mathrm{a}$ & $42,90 \mathrm{a}$ & $43,75 \mathrm{a}$ & $43,00 \mathrm{a}$ & $42,75 \mathrm{a}$ \\
Testemunha & & & & & & & \\
\hline CV $(\%)-21,06$ & & & & &
\end{tabular}

1/ - Médias seguidas da mesma letra na coluna não diferem entre si a 5\% de probabilidade, pelo teste de Tukey.

DAT - Dias após tratamento.

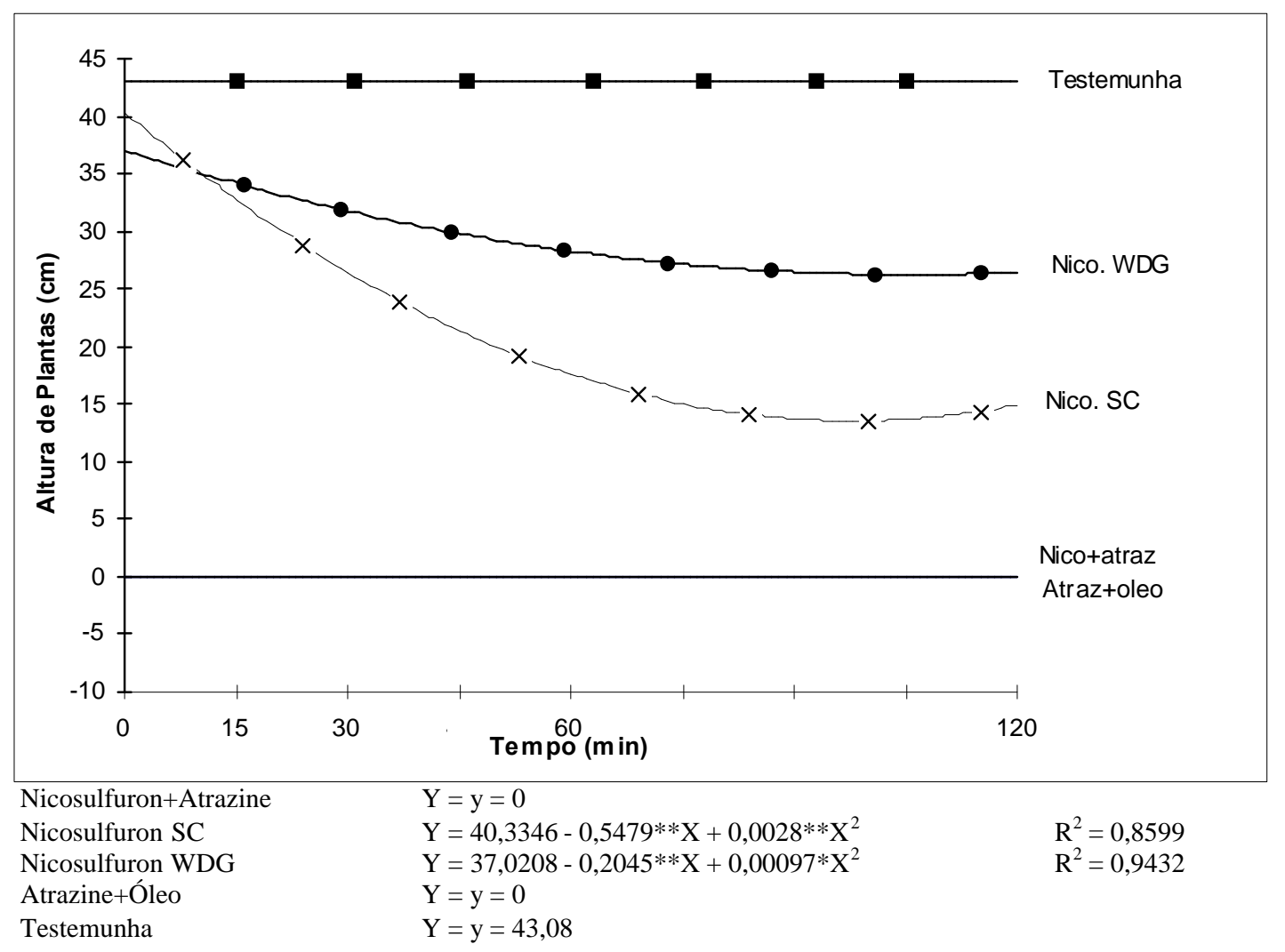

FIGURA 3. Altura de plantas (em $\mathrm{cm}$ ), de Bidens pilosa aos 28 DAT, em função do tempo de aplicação de 30 mm de chuva, em solo úmido. Viçosa, MG, 1996. 
TABELA 4 - Altura de plantas $(\mathrm{cm})^{1}$ de Bidens pilosa aos 28 DAT, em função da ocorrência de $30 \mathrm{~mm}$ de chuva aos $0 ; 15 ; 30 ; 60$ e 120 min após aplicação dos tratamentos sobre plantas cultivadas sob estresse hídrico. Viçosa, MG, 1996.

\begin{tabular}{lccccccc}
\hline \multirow{2}{*}{ Herbicidas+Testemunha } & Doses & \multicolumn{5}{c}{ Tempo: aplicação / ocorrência de chuva simulada } \\
\cline { 3 - 8 } & (g.i.a./ha) & 0 min. & 15 min. & 30 min. & 60 mnin. & 120 min. \\
\hline Nicosulfuron+Atrazine & $40+1000$ & $0,00 \mathrm{c}$ & $0,00 \mathrm{~d}$ & $0,00 \mathrm{c}$ & $0,00 \mathrm{~d}$ & $0,00 \mathrm{~d}$ \\
Nicosulfuron SC & 60,0 & $20,50 \mathrm{~b}$ & $19,50 \mathrm{c}$ & $25,0 \mathrm{~b}$ & $25,25 \mathrm{~b}$ & $27,25 \mathrm{~b}$ \\
Nicosulfuron WDG & 60,0 & $23,00 \mathrm{~b}$ & $28,00 \mathrm{~b}$ & $21,25 \mathrm{~b}$ & $18,25 \mathrm{c}$ & $18,75 \mathrm{c}$ \\
Atrazine+ Óleo & $2400+1800$ & $000 \mathrm{c}$ & $0,00 \mathrm{~d}$ & $0,00 \mathrm{c}$ & $0,00 \mathrm{~d}$ & $0,00 \mathrm{~d}$ \\
Testemunha & ------ & $40,75 \mathrm{a}$ & $38,75 \mathrm{a}$ & $42,25 \mathrm{a}$ & $38,75 \mathrm{a}$ & $42,25 \mathrm{a}$ \\
CV $(\%)-25,81$ & & & & & & & \\
\hline
\end{tabular}

1/ - Médias seguidas da mesma letra na coluna não diferem entre si a 5\% de probabilidade, pelo teste de Tukey.

DAT - Dias após tratamento.

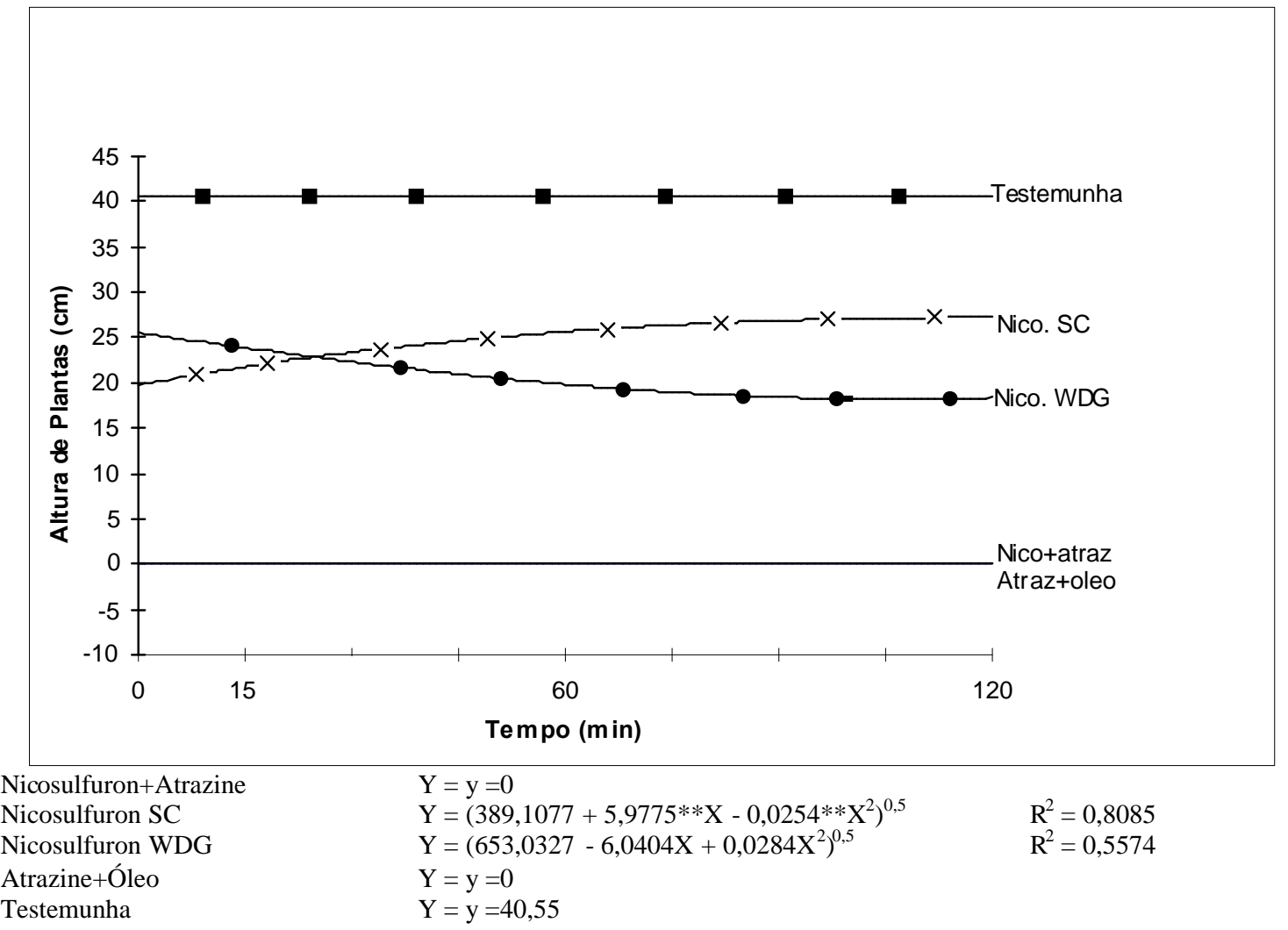

FIGURA 4. Altura de plantas (em $\mathrm{cm}$ ), de Bidens pilosa aos 28 DAT, em função do tempo de aplicação de $30 \mathrm{~mm}$ de chuva, em condições de baixa umidade do solo (estresse hídrico).Viçosa, MG, 1996. 
TABELA 5. Biomassa seca (g) de plantas de milho (Zea mays L.) em presença de Brachiaria plantaginea e Bidens pilosa, aos 28 DAT, em função da ocorrência de $30 \mathrm{~mm}$ de chuva aos 0; 5; 30; 60 e 120 min após aplicação dos herbicidas, em pós-emergência, em condições de solo úmido. Viçosa, MG,1996.

\begin{tabular}{|c|c|c|c|c|c|c|}
\hline \multirow{2}{*}{ Herbicidas+Testemunha } & \multirow{2}{*}{$\begin{array}{c}\text { Doses } \\
\text { (g.i.a./ha) }\end{array}$} & \multicolumn{5}{|c|}{ Tempo: aplicação / ocorrência de chuva simulada } \\
\hline & & 0 min. & 15 min. & $30 \mathrm{~min}$. & 60 mnin. & 120 min. \\
\hline Nicosulfuron+Atrazine & $40+1000$ & $41,12 \mathrm{~b}$ & $37,22 \mathrm{~b}$ & $43,97 \mathrm{ab}$ & $43,80 \mathrm{~b}$ & 45,78 a \\
\hline Nicosulfuron SC & 60,0 & $32,07 \mathrm{~b}$ & $37,65 \mathrm{~b}$ & $42,55 \mathrm{ab}$ & $40,20 \mathrm{~b}$ & $44,77 \mathrm{a}$ \\
\hline Nicosulfuron WDG & 60,0 & $36,73 \mathrm{~b}$ & $37,78 \mathrm{~b}$ & $43,15 \mathrm{ab}$ & $41,52 \mathrm{~b}$ & $32,37 \mathrm{~b}$ \\
\hline Atrazine+ Óleo & $2400+1800$ & $35,17 \mathrm{~b}$ & $36,30 \mathrm{~b}$ & $39,32 \mathrm{~b}$ & $35,90 \mathrm{~b}$ & $41,30 \mathrm{a}$ \\
\hline Testemunha sem P.D. & ------- & $51,55 \mathrm{a}$ & $51,05 \mathrm{a}$ & 48,35 a & $50,40 \mathrm{a}$ & 49,47 a \\
\hline Testemunha com P.D. & .......... & $31,97 \mathrm{~b}$ & $29,00 \mathrm{~b}$ & $29,67 \mathrm{c}$ & $32,95 \mathrm{~b}$ & $31,05 \mathrm{~b}$ \\
\hline CV $(\%)-(14,19)$ & & & & & & \\
\hline
\end{tabular}

TABELA 6. Biomassa seca de plantas de Bidens pilosa aos 28 DAT, em função da ocorrência de chuva aos $0 ; 15 ; 30 ; 60$ e 120 min após aplicação dos tratamentos sobre as plantas cultivadas sob estresse hídrico. Viçosa, MG,1996.

\begin{tabular}{|c|c|c|c|c|c|c|}
\hline \multirow{3}{*}{ Herbicidas+Testemunha } & \multirow{3}{*}{$\begin{array}{c}\text { Doses } \\
\text { (g.i.a./ha) }\end{array}$} & \multicolumn{5}{|c|}{ Tempo: aplicação / ocorrência de chuva simulada } \\
\hline & & 0 min. & $15 \mathrm{~min}$. & $30 \mathrm{~min}$. & $60 \mathrm{~min}$. & $120 \mathrm{~min}$. \\
\hline & & & Biomassa & Seca & & \\
\hline Nicosulfuron+Atrazine & $40+1000$ & $0,0 \mathrm{c}$ & $0,0 \mathrm{~d}$ & $0,0 \mathrm{c}$ & $0,0 \mathrm{~d}$ & $0,0 \mathrm{~d}$ \\
\hline Nicosulfuron SC & 60,0 & $1,9 \mathrm{~b}$ & $2,0 \mathrm{c}$ & $3,1 b$ & $3,1 \mathrm{~b}$ & $3,3 b$ \\
\hline Nicosulfuron WDG & 60,0 & $2,3 b$ & $3,3 b$ & $2,2 b$ & $1,9 \mathrm{c}$ & $1,7 \mathrm{c}$ \\
\hline Atrazine+ Óleo & $2400+1800$ & $0,0 \mathrm{c}$ & $0,0 \mathrm{~d}$ & $0,0 \mathrm{c}$ & $0,0 \mathrm{~d}$ & $0,0 \mathrm{~d}$ \\
\hline Testemunha & ------- & $6,2 \mathrm{a}$ & $6,0 \mathrm{a}$ & $7,1 \mathrm{a}$ & $5,8 \mathrm{a}$ & $6,8 \mathrm{a}$ \\
\hline CV $(\%)-(37,71)$ & & & & & & \\
\hline
\end{tabular}

1/ - Médias seguidas da mesma letra na coluna não diferem entre si a 5\% de probabilidade, pelo teste de Tukey.

DAT - Dias após tratamento. 
Influência de chuva simulada após aplicação de herbicidas em pós-emergência, sobre o controle de plantas daninhas, em solo com dois níveis de umidade
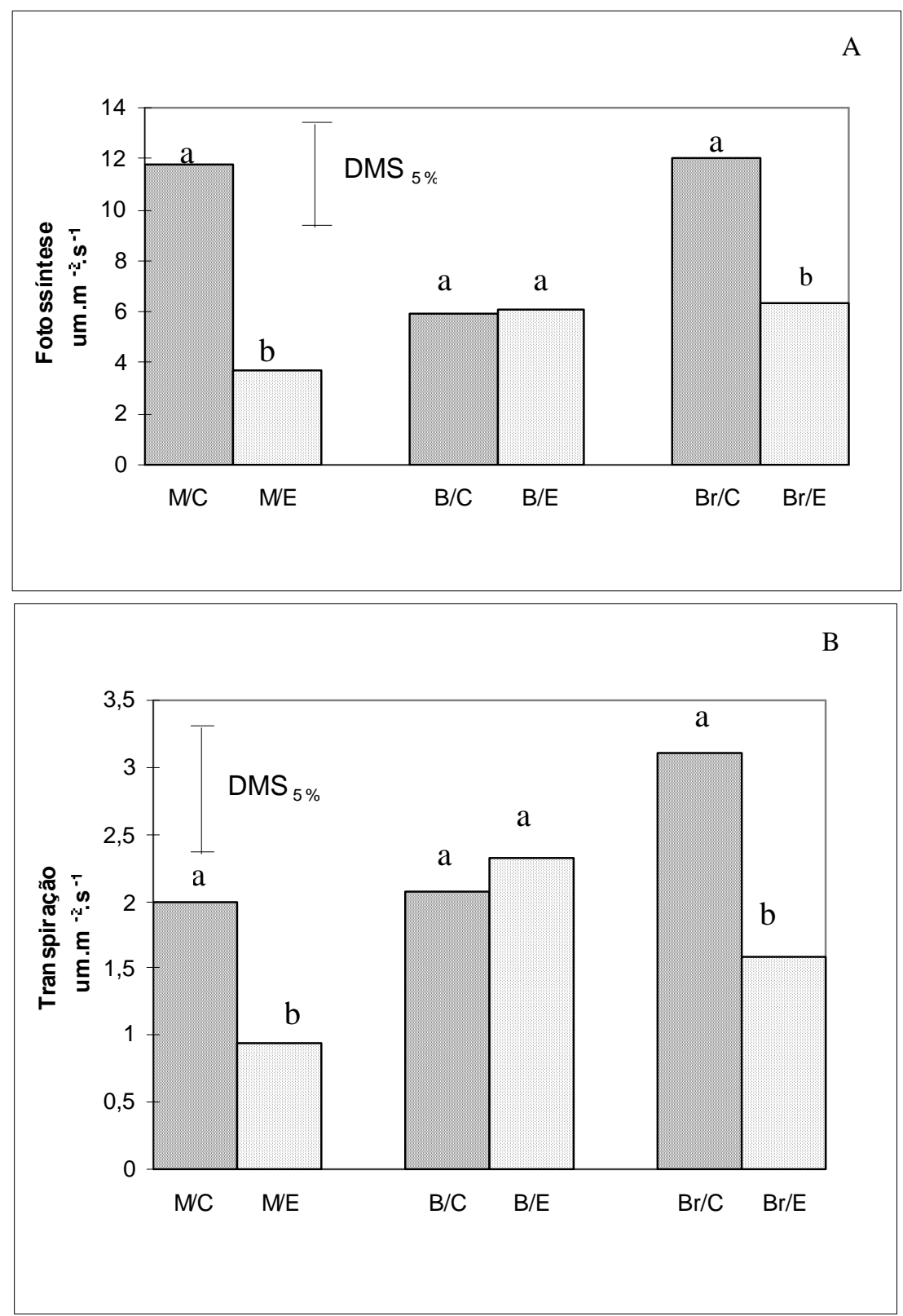

FIGURA 5. Fotossíntese (A) e transpiração (B) obtidas por ocasião da aplicação dos herbicidas sobre as plantas de milho (M), picão-preto (B) e capim-marmelada (Br), crescidas em um mesmo vaso, em solo úmido (Controle-C) e sob estresse hídrico (E) no solo. Viçosa, MG, 1996. 


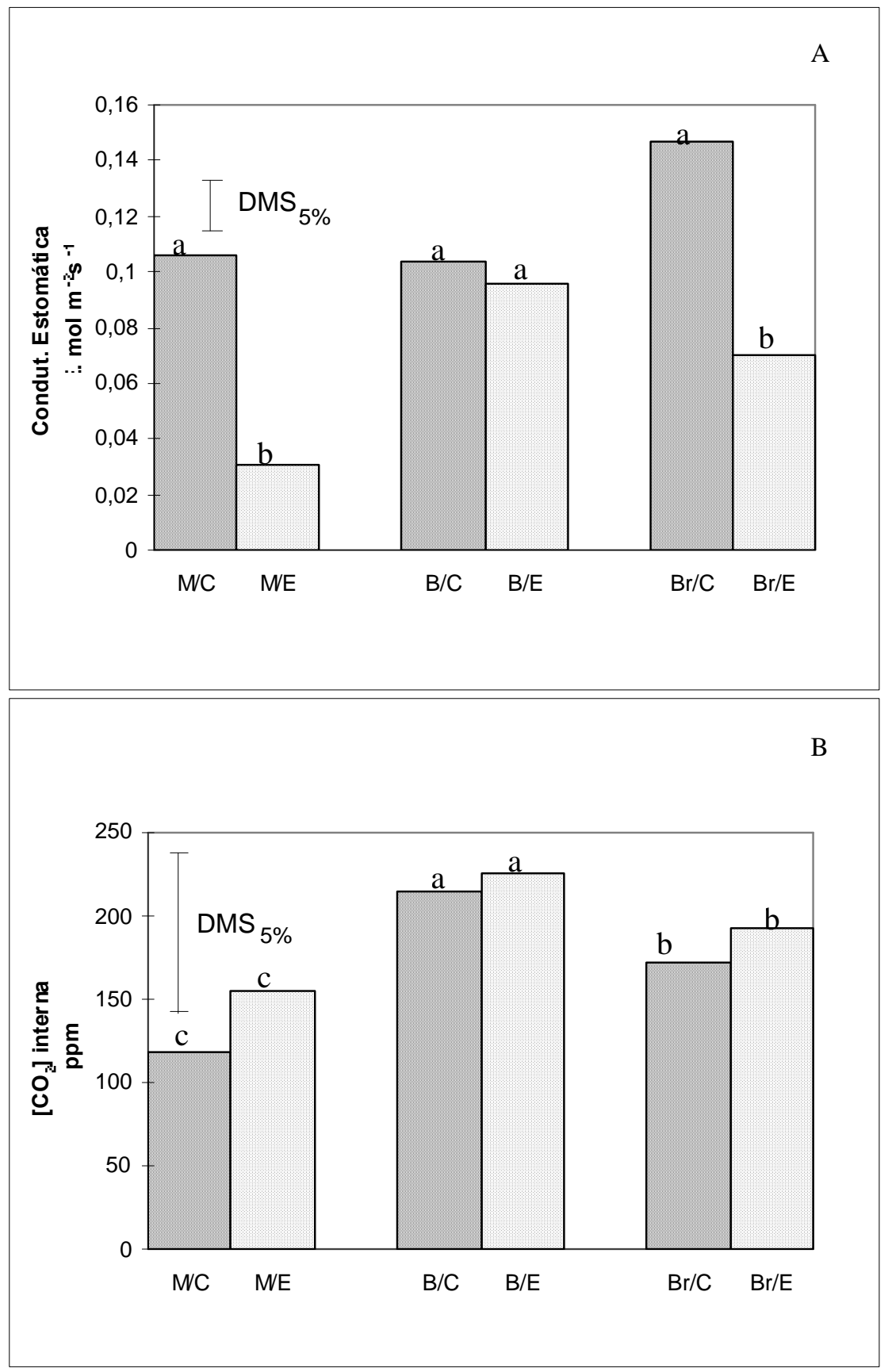

FIGURA 6. Condutância estomática (A) e concentração interna de $\mathrm{CO}_{2}(\mathrm{~B})$, obtidas por ocasião da aplicação dos herbicidas sobre as plantas de milho (M), picão-preto (B) e capim-marmelada $(\mathrm{Br})$, crescidas em um mesmo vaso, em solo úmido (Controle-C) e sob estresse hídrico no solo (E). Viçosa, MG, 1996. 


\section{LITERATURA CITADA}

ANDERSON, M. D., ARNOLD, W. E. Weed control in sunflowers (Helianthus annus) with desmediphan and phenmediphan. Weed Sci., v.32, p. 310-314, 1984.

BEHRENS, R., ELAKKAD, M. A. Influence of rainfall on the phytotoxicity of foliarly applied 2,4-D. Weed Sci., v. 29 p. 349-355, 1981.

BRASIL. Ministério da Agricultura. Regras para análise de sementes. Brasília, DF: LANARV, SNAD, MA, 1992. 365 p.

DEUBER, R. Ciência das plantas daninhas: fundamentos. Jaboticabal: FUNEP, UNESP, 1992, v. 1

DEVINE, M.D., BANDEEN, J.D., McKERSEI, B.D. Temperature effects on glyphosate absorption, translocation and distribution in quakgrass (Agropyron repens). Weed Sci., v. 31, p.461-464, 1983.

FERREIRA, F. A., SILVA, A. A. da, FERREIRA, L. R. Efeitos do nicosulfuron, em duas formulações, sobre o controle de plantas daninhas na cultura do milho (Zea mays L.). In: Ciência e Agrotecnologia, v. 20, n. 1, p.19-24, 1996.

GREEN J. M., ULRICH, J. F. Response to corn (Zea mayz L.) inbrids and hibrids to sulfonilu réias herbicides. Weed Sci., v. 41, p. 508-516, 1993

HAMMERTON, J. L. Environmental factores and susceptibility to herbicicides. Weeds, v. 15, p. 330-336, 1967.

HARRISON, S.K., WAX, L.M. Adjuvant effects on absorption, translocation, and metabolism of Haloxyfop - Methyl in corn (Zea mays). Weed Sci., v.2, 1986.
HESS, F. D. Absorption. In: HERBICIDE action. Intensive course on the activity selectivy, behavior and fate of herbicides in Plants and Soils. West Lafayette: Purdue University, 1994, p.13-31.

KELLS, J.J., MEGGITT, F.W., PENNER, D. Absorption, translocation and activity of Fluazifop-butil as influenced by plant growth stage and enviroment. Weed Sci., v. 32, p. 143-149, 1984.

KRAMER, P. J. Water relations of plants. London: Academic Press, 1987. 489p.

PEREGOY, R. S., KITCHEN, L. M., JORDAN, P. W. et al. Moisture stress effects on the absorption, translocation, and metabolism of haloxyfop in johnsongrass (Sorghum halepense) and large crabgrass (Digitaria sanguinalis). Weed Sci., v. 38, p.331-337, 1990.

PINTO, J. J. O., ALMEIDA, R. HASSMANN, J. S. et al. Avaliação do herbicida nicosulfuron aplicado em pós-emergência na cultura do milho. In: CONGRESSO BRASILEIRO DE HERBICIDAS E PLANTAS DANINHAS, 19, 1993, Londrina. Resumos... Londrina: Iapar,1993. p. 152.

RETZINGER, J. E.J., ROGERS, R.L., MOWERS, R.P. 1983. Performance of BAS 9052 applied to johnsograss and soybeans. Weed Sci., v.31, p.796-800, 1983.

SILVA, A. A da, ALTOÉ, I. F. Efeitos do nicosulfuron sobre a cultura do milho e no controle de plantas daninhas. In: CONGRESSO BRASILEIRO DE HERBICIDAS E PLANTAS DANINHAS, 19, 1993, Londrina. Resumos... Londrina: Iapar, 1993. p. 153.

SILVA, A. A. da, MELHORANÇA, A. L. Controle de plantas daninhas na cultura do 
milho. In: RECOMENDAÇÕES técnicas para a cultura do milho para Mato Grosso do Sul. Dourados: EMBRAPA, 1991 p.114127. ( Circular Técnica, 20 ).

TAIZ, L., ZEIGER, E. Plant physiology. California: The Benjamim/Cummings, 1991. p. 537.

VELINI, E. D., TRINDADE, M. L. B. Comportamento de herbicidas na planta.
Época de aplicação de herbicidas. In: SIMPÓSIO NACIONAL SOBRE MANEJO INTEGRADO DE PLANTAS DANINHAS EM HORTALIÇAS, 1992, Botucatu, Anais... Botucatu: UNESP, FEPAF, 1992. p.65-86.

WALDECKER, M. A., WYSE, D. L. Soil moisture effects on glyfhosate absorption and translocation in common milk-weed (Asclepias syriaca). Weed Sci., v. 33, p. 299305, 1985. 